AsCLEPIO. Revista de Historia de la Medicina y de la Ciencia

66 (2), julio-diciembre 2014, p057

ISSN-L:0210-4466

http://dx.doi.org/10.3989/asclepio.2014.21

DOSSIER: BIOPODER Y DETERMINISMOS EN SUDAMÉRICA DURANTE EL SIGLO XX / DOSSIER: BIOPOWER AND DETERMINISM IN SOUTH AMERICA DURING THE TWENTIETH CENTURY

\title{
NEUROLIBERALISMO: LA CONFRONTACIÓN COMO MECANISMO DE SELECCIÓN SOCIAL
}

\author{
Hugo E. Biagini \\ Universidad Nacional de Lanús, Argentina \\ hbiagini@speedy.com.ar \\ Diego A. Fernández Peychaux \\ Conicet, Argentina \\ dfernandezpeychaux@gmail.com
}

Recibido: 30 septiembre 2013; Aceptado: 14 abril 2014.

\begin{abstract}
Cómo citar este artículo/Citation: Biagini, Hugo E. y Diego A. Fernández Peychaux (2014), “Neuroliberalismo: la confrontación como mecanismo de selección social" Asclepio, 66 (2): p057. doi: http://dx.doi.org/10.3989/asclepio.2014.21

RESUMEN: El presente artículo recurre a la nomenclatura alternativa de 'neuroliberalismo' para explicitar cómo el discurso hegemónico del mercado elabora una 'fantasía ideológica' que, apoyada en lo que denominamos ética gladiatoria, resignifica los conceptos clásicos del liberalismo. En la primera parte, nos centraremos en la descripción del neuroliberalismo como una teoría de selección social. En la segunda parte, buscamos explicitar su operatividad como aparato de adoctrinamiento aplicado sobre individuos vulnerables a unas condiciones de posibilidad que se escapan a su control. Así, la globalización neoliberal se perpetúa alborozadamente consentida por individuos reprimidos por una satisfacción preadaptada al paradigma de la lucha por la existencia.
\end{abstract}

PALABRAS CLAVE: Ayn Rand; Ludwig Von Mises; Fantasía Ideológica; Normalización; Sujeción.

\section{NEUROLIBERALISM: CONFRONTATION AS A MECHANISM OF SOCIAL SELECTION}

ABSTRACT: This article resorts to the alternative nomenclature of 'neuroliberalism' to explicitly state how the hegemonical discourse of market produces an ideological fantasy which, supported by a 'gladiatorial ethics', redefines classical concepts of liberalism. In the first part, we shall focus on the description of neuroliberalism as theory of social selection. In the second part, we aim to specify its operativity as apparatuses of indoctrination applies to individuals vulnerable to possibility conditions beyond their control. Thus, the neoliberal globalization is cheerfully applied through the consent of individuals who are repressed by a pre-adapted satisfaction to the paradigm of the struggle for existence.

KEY WORDS: Ayn Rand; Ludwig Von Mises; Ideological Fantasy; Normalization; Subjection.

Copyright: ( 2014 CSIC. Este es un artículo de acceso abierto distribuido bajo los términos de la licencia Creative Commons Attribution-Non Commercial (by-nc) Spain 3.0. 


\section{INTRODUCCIÓN}

En un sugestivo pasaje de Rayuela, Julio Cortázar rememora la teoría de León Chestov sobre las peceras con tabiques móviles. En esta alegoría los peces, ávidos por evitar frotarse la nariz con algo desagradable, jamás se decidirían a pasar al otro lado. Poco importa, afirma el autor ucraniano, la remoción de los límites sólidos de su pequeño universo. "Llegar hasta un punto del agua, girar, volverse, sin saber que ya no hay obstáculo, que bastaría seguir avanzando» (Cortázar, 1963 , p. 107). La naturalización del control extinguiría la necesidad carcelaria de la pecera. Hay que advertir, sin embargo, que la disciplina de la escena se explica menos por la capacidad productiva del tabique imaginario, que por unos efectos en los que se encuentran involucrados también los peces. Al nadar en círculos dentro de un espacio virtual, sus cuerpos ya no son el lugar de investidura de una potencia que los domina, sino partícipes necesarios de una repetitividad controlada de esas relaciones de poder. De modo que la efectividad de la norma se reitera en un proceso de sujeción ambivalente en el que pareciera que el sometimiento del deseo exige e instituye el deseo por el sometimiento.

El consentimiento brindado a la propia sujeción ha sido objeto de múltiples elaboraciones y explicaciones desde la publicación del Discurso de la servidumbre voluntaria o el contra uno de Étienne de La Boétie en el siglo XVI. En el presente trabajo, aunque no pretendamos ninguna síntesis grandiosa, buscamos dar cuenta del funcionamiento de esa desventura ${ }^{1}$, pero no desde el diagnóstico de un fallo congénito de nuestra hechura, sino como el resultado, en este caso, del modelo civilizador del neoliberalismo. La alegoría de la pecera, no describiría a sujetos imbuidos de un temor natural para adentrarse en los espacios abiertos de la libertad, sino un escenario en el que la norma produce subjetividad explotando la dependencia primaria de una existencia social. De ahí que, una vez caídos los tabiques económicos y políticos que en Nuestramérica ${ }^{2}$ representaron durante más de seis décadas sus expedientes racionalizadores, los individuos sigan bregando por imponerse una subjetividad ad hoc a las necesidades del mercado.

En otras palabras, quisiéramos arriesgar dando un paso más a la crítica tradicional al liberalismo y explicitar cómo el neoliberalismo elabora lo que Žižek llama una "fantasía ideológica» que, articulada en lo que denominaremos 'ética gladiatoria', busca resignificar los conceptos clásicos del liberalismo (Žižek, 2010a, pp. 201-256). En su versión neo las categorías sociales de éxito/fracaso pretenden unificar el horizonte global del campo ideológico del liberalismo. La particularidad de esta fetichización del exitoso radica en no limitarse a repudiar la memoria histórica del sufrimiento del Otro. Busca, en cambio, activar la relación ilusoria que los sujetos desarrollan con su propia satisfacción y bienestar.

\section{LA SUJECIÓN VOLUNTARIA}

La capacidad productiva de sujetos dóciles no acontece de una vez para siempre, sino que se despliega, según el análisis de M. Foucault, una «economía del poder» microfísica: serie de tácticas, maniobras, estrategias siempre tensas y en actividad que no acontecen ni en un instante, ni desde un único emplazamiento de clase. Este poder, por tanto, no es una 'propiedad' sino un 'ejercicio' que, a raíz de su propia definición, recoge en sus efectos las posiciones de quien domina y del dominado (Foucault, 2002, pp. 18 y ss.). El proceso responde a una ambivalencia constitutiva. Por un lado, ningún individuo se exime de padecer la subjetivación. Pero, por el otro, esos mismos sujetos asumen el poder que los somete para garantizar la persistencia en su ser social.

La repetibilidad necesaria de las relaciones de poder incurre en el riesgo de ver alterada la intención en el resultado, abriendo huecos, rajaduras, fisuras en los que ejercer la libertad. «La repetición o, mejor dicho, la iterabilidad, se convierte por tanto en el nolugar de la subversión, en la posibilidad de una reencarnación de la norma subjetivadora que redirija su normatividad» (Butler, 2010, p. 113). Aunque resulta evidente que desbordar los efectos deseados no implica reconducir o reformular la norma, en los debates neoliberales sobre el ejercicio de la libertad el agente siempre se presenta imbuido de un poder autónomo que niega cualquier condicionamiento. Esto lleva, por ejemplo, a proferir 'aceptabilidad moral' al contrato de compra venta en el que un individuo se entrega a sí mismo como esclavo. Las relaciones de poder que puedan influir en dicha negociación quedan silenciadas, incluso en pleno siglo XXI, por la vigencia positiva del acuerdo 'voluntario's. En última instancia, la delimitación de la potencia es rigurosa responsabilidad de las circunstancias personales "congénitas o adquiridas» (Mises, 2011, p. 26).

En este contexto, las obras de Ludwig von Mises y Ayn Rand son ejemplo de la descripción neoliberal del mundo peligroso en el cual el mercado se constituye en el sistema objetivo de selección de la especie humana. Su panegírico del combate articula la equivalencia entre la victoria y el bien moral. Los conceptos de 'éxito', 'virtud' y 'egoísmo' se emplean sin solución de continuidad en un discurso pergeñado para crear las condiciones de aceptabilidad de un orden que requiere ignorar los efectos materiales ajenos y propios del enfrentamiento constante. A continuación nos detendremos en la descripción de La mentalidad anticapitalista (1956) de Mises y La rebelión del Atlas (1957) de Rand. 


\section{2.a. Mises: la libertad para luchar}

En La Mentalidad Anticapitalista de Ludwig von Mises se argumenta que aquello que impide la correcta apreciación de las mieles del mercado estriba en un desarreglo psíquico o mental del observador. Recurriendo a un positivismo hiperbólico, señala cada uno de los logros que el capitalismo ha alcanzado en las sociedades bien pensantes que le han dejado florecer. Los 'menos aventajados' - fracasados en la lucha por una posición social- son sujetos asediados por una idiocia mental, fallas cerebrales para los negocios o, simplemente, afectados por una especie de resentimiento o frustración psicológica que los mueve al odio hacia aquellos que les han vencido.

Advierte el sujeto, tal vez de modo subconsciente decíamos antes-, que fue su propia insuficiencia lo que le impidió alcanzar las altas metas por él ambicionadas; cónstale la limitación de su capacidad intelectual y la insuficiencia de su capacidad de trabajo; pero él procura ocultar la verdad, a sí mismo y a sus semejantes, buscando conveniente víctima propiciatoria. Se consuela pensando que el fracaso no se debió a su personal incapacidad, sino a la injusta condición de la organización económico social prevalente (Mises, 2011, p. 90).

Frente a la ilusión psicológica que exonera la responsabilidad individual, Mises despliega sus argumentos para brindar legitimidad a la pugna y sus resultados. La primera premisa consiste en negar los derechos humanos como una característica innata de la humanidad. "Se parte siempre de un error grave, pero muy extendido: el de que la naturaleza concedió a cada uno ciertos derechos inalienables, por el solo hecho de haber nacido" (Mises, 2011, p. 79). Una vez establecido que todos los seres humanos ingresan en el mundo exentos de deberes mutuos, resulta imperioso reconocer, en segundo lugar, que «la economía de mercado constituye un continuo proceso de selección social; determina la posición y los ingresos de cada uno" (Mises, 2011, pp. 94-96). Las circunstancias objetivas -i.e. despojadas de los análisis indignantes de los anticapitalistas- están gobernadas por una naturaleza que "escatima cuántos bienes el hombre precisa para sobrevivir». La humanidad se encuentra cercada «por malignos seres, tanto animales como vegetales, dispuestos siempre a dañarnos; las fuerzas naturales se desatan en nuestro perjuicio; la mera pervivencia hemos de reconquistarla a diario» (Mises, 2011, p. 79).

La conclusión de ambas premisas es que la categoría o posición social obtenida a través del 'supremo organismo' del mercado depende exclusivamente de los onerosos esfuerzos personales por reconquistar diariamente el botín obtenido en la competencia con el resto de la humanidad y la naturaleza. El pandórico regalo de la inteligencia - afirma Mises - confie- re una posición natural que se traduce en una categoría social. El fracaso se sigue de las incapacidades personales. Al igual que los ancestros que habitaban cavernas, el hombre contemporáneo debe aceptar el control demográfico tradicional: hambrunas, pestes, mortalidad infantil, etc. (Hayek, 1981). El único medio para substraerse de tan ominoso destino histórico consiste en luchar por aquellos símbolos de bienestar que le confieran una mejor ubicación en la división de trabajo. Descender en el escalafón de los exitosos supone, concomitantemente, decrecer por propia responsabilidad en la cadena trófica de la naturaleza. Una mala posición en un contexto carente de derechos humanos -i.e. caer vencido por otro más avezado en granjearse aprecio del público compradorimplica la 'extinción' en términos biológicos y sociales.

En esa traslación entre la lucha por la supervivencia de los ancestros primitivos y los consumidores del siglo XX, Mises afirma que lo humano proviene del deseo. Este homo agens, a diferencia de los otros animales, se caracteriza por su incesante búsqueda de símbolos sociales que rubriquen el éxito y la posición alcanzada. Cancelar o suspender la pugna denota irracionalidad, perder la existencia social. La dinámica de la lucha con el entorno no se detiene ya que el bienestar obtenido carece de un efecto liberador, sino que realimenta la sujeción a un sistema de producción que no se controla ni dirige (Mises, 2011, p. 21 y p. 43-45).

Este análisis de la realidad humana desde la perspectiva individual sirve, a su vez, para explicar y legitimar, según Mises, el imperialismo colonial. Elogia la capacidad de ahorro de las sociedades occidentales - entiéndase Europa y Estados Unidos- durante los siglos XVII y XVIII, porque de ella se derivó la acumulación de capital necesario para alcanzar la posición suprema actual de entre todas las naciones.

La verdad, contrariamente a lo supuesto, es que ese capitalismo del laissez faire, que para condenarlo "por razones de moral» el documento del Consejo Mundial tergiversa, fue el instrumento que enriqueció a los países occidentales, mediante la creación de capital, posteriormente invertido en máquinas y herramientas. Si asiáticos y africanos no permitieron, por las razones que fuere, la aparición de un capitalismo autóctono, allá ellos; ése es su problema. Occidente no tiene la culpa de nada; ya hizo bastante procurando, durante repetidas décadas, alumbrar la correcta vía (Mises, 2011, p. 80)

El neoliberalismo que el autor defiende se desnuda en todo su cinismo. Entiéndase bien: no oculta que la acumulación de capital occidental está cimentada sobre el subconsumo de millones de seres humanos condenados a la muerte por inanición. El argumento de la lucha a vida o muerte explica que «el descubrimiento de los yacimientos de oro y plata de América, el exterminio, la esclavización y el sepultamiento 
en las minas de la población aborigen, el comienzo de la conquista y el saqueo de las Indias Orientales, la conversión del continente africano en cazadero de esclavos negros» son hechos que refrendan la validez de la economía capitalista que premia a los más perspicaces (Marx, 1999, pp. 607-649) ${ }^{4}$. Los vencedores obtienen una mejor posición en relación con el resto de 'zánganos' que pretenden robarles sus trofeos por 'razones morales'. El deterioro de los términos de intercambio entre los países pobres y ricos ha de leerse con esta clave gladiatoria: la racional búsqueda incesante del aumento del bienestar.

Tales diatribas contra las mentalidades subnormales de los anticapitalistas no se detienen en el campo especulativo.

Subproducto del moderno capitalismo son todos esos frívolos intelectuales quienes actualmente, por doquier, pululan; su entrometido y desordenado actuar repugna; solo sirven para molestar. Nada se perdería si, de algún modo, cupiera acallarlos, clausurando sus círculos y agrupaciones (Mises, 2011, p. 100).

A párrafo seguido se aclara que dicha iniciativa resultaría imposible y contraproducente. Mas el convencimiento sobre la necesidad del pluralismo político no ha de confundirse con una preferencia por la democracia. En el siglo XX, al igual que en los siglos XVII y XVIII, el capitalismo se desarrolla apoyado por la brutalidad dictatorial aunque sus defensores se encarguen de ocultar bajo la alfombra esos «suplementos obscenos del poder» (Žižek 2010b, pp. 11-39). No solo Mises, sino sus más allegados discípulos - por ejemplo, Milton Friedman y Friedrich Hayek - apoyaron los regímenes autoritarios que, al compás de su cancioneta libertaria, buscaban desplazar a esos pululadores de lo social, mentalidades precarias, deficientes, vanas, que impedían el progreso económico de un capital que tiene por único objetivo la acumulación de 'ahorro social'.

La participación de Milton Friedman en la dictadura cívico-militar de Augusto Pinochet resulta harto conocida. Incluso el autor, en el libro sincericida Friedman on Galbraith, recomienda a los ingleses una política del shock idéntica a la chilena, de la cual se reconoce partícipe necesario (Friedman, 1977, pp. 46-47). La 'modernización chilena' contó, a su vez, con otro gran aval teórico en Friedrich Hayek. En una famosa entrevista al periódico El Mercurio el 19 de abril 1981, justifica la ruptura del orden constitucional al identificar los tres años de gobierno de la Unidad Popular de Salvador Allende con un estado de naturaleza hobbesiano carente de ley y justicia. "Cuando no hay normas - sostuvo-, alguien tiene que crearlas ${ }^{5}$. Las visitas a Chile estuvieron precedidas por una anterior a Buenos Aires, en 1977, invitado por la Academia Nacional de Ciencias y la Bolsa de Comercio, donde impartió conferencias de introducción a su pensamiento (Hayek, 1978).
La colaboración de Mises en el proceso iniciado con la dictadura 'libertadora' de Aramburu y Lonardi se materializó en Argentina a través de una serie de seis conferencias que contribuyeron al equívoco entre democracia y dictadura (Mises, 2006, p. 54). ${ }^{6}$ La democracia neoliberal no legitima a los regímenes políticos que recurren a los comicios electorales para elegir representantes, a menos que los garantes de la libertad de mercado cumplan su tarea sin importar los 'caprichos' de mayorías 'tumultuosas e ignorantes'. Los anfitriones argentinos del autor austríaco recurren a sofisticadas cabriolas retóricas para llamar 'dictador' y 'genocida' a Juan Domingo Perón 7 . El agasajado les asistió, al menos, en una de esas volteretas durante sus conferencias. No fue una distracción. Maestro de escuela, viajó a Argentina para refrendar a los ideólogos de los peores procesos represivos de su historia.

The socialist nations have arrogated to themselves the term democracy. The Russians call their own system a People's Democracy; they probably maintain that the people are represented in the person of the dictator. I think that one dictator, Juan Peron here in Argentina, was given a good answer when he was forced into exile in 1955. Let us hope that all other dictators, in other nations, will be accorded a similar response (Mises 2006, p. 54) ${ }^{8}$.

El intervencionismo peronista en la libertad de mercado explica el fin de la 'democracia' dineraria. Al regular la economía, los miembros del grupo de presión -i.e. el Partido Justicialista - se hacen con el control del gobierno arrogándose una mayor sabiduría que la del ciudadano común para definir el sistema de precios. El remedio para evitar esa profusión de servidumbre - afirma Mises en esa conferencia- consiste en 'forzar al exilio' a estos dictadores.

Las intervenciones en Buenos Aires del autor austríaco se produjeron entre el 3 y 16 de junio de 1959. Es decir, una vez que los verdaderos dictadores habían entregado el gobierno al presidente electo Arturo Frondizi. Sin embargo, los militares mantuvieron el control sobre un poder ejecutivo condicionado. Entre el 1 de mayo de 1958 y el 29 de marzo de 1962 se sucedieron veintiséis asonadas militares y seis intentos de golpe de estado. Estas presiones estuvieron encaminadas a corregir cualquier decisión autónoma del presidente. El 25 de junio de 1959, menos de diez días después de la última conferencia de Mises ampliamente difundida en la prensa local, asumió el Ministerio de Economía Álvaro Alsogaray. Este militar, economista y político había sido Subsecretario de Comercio y luego Ministro de Industria durante el gobierno de Lonardi y Aramburu. Durante su nueva gestión el flamante Ministro impuso el diagnóstico neoliberal, abandonando la línea desarrollista de Rogelio Frigerio. El objetivo del gobierno ya no apuntaría al desarrollo de sus fuerzas productivas, sino a contener 
la inflación aun a costa de iniciar procesos regresivos de distribución de la renta o profundizar el deterioro de los términos de intercambio. Dos décadas después, cuando el neoliberalismo estaba instalado en el lugar de 'sentido común', será el mismo Alsogaray quien acompañe a Hayek en las entrevistas mencionadas dadas en la Bolsa de Comercio en 1977.

En resumen, estas deformaciones del canon liberal pudieron implementarse políticamente por estar sustentadas en una devaluación concomitante de los derechos humanos y del pluralismo. La libertad para pugnar por una posición en el mercado -la supervivencia - sirve como fantasía que impide reaccionar ante las peores atrocidades. Vale recordar que en los países que más han logrado acercarse al neoliberalismo puro, sus gobiernos estaban 'raptados' por dictaduras cívico-militares. La oposición popular resistió las reformas, dejándolas a medio camino. Sin embargo, en tanto las sociedades se permearon con las directrices básicas del neoliberalismo este halla las vías para responder a las democracias degradadas sin alterar las pautas de normalización que garantizan la continuidad de la expoliación.

\section{2.b. Ayn Rand: héroes inmaculados}

La escritora estadounidense de origen ruso fue un ariete fundamental del 'nuevo' liberalismo en su defensa del capitalismo. Pensarla como una simple guionista o novelista distorsionaría su verdadera importancia política. Desde mediados del siglo XX mantuvo una fluida relación con filósofos, economistas y políticos como Alan Greenspan o Henry Hazlitt, pero en particular interesa destacar su contribución a la difusión de la obra de Mises y de la Escuela Austríaca de economía dentro del público masivo ${ }^{9}$. La esposa del autor austríaco - Margit von Mises- sostiene que no solo las teorías de su marido encontraron en Rand una de sus más fervorosas creyentes, sino que además continuamente citaba sus trabajos y conferencias (Mises, 1984, p. 134). Confirma sus palabras el hecho de que la gran novela de la autora - La rebelión del Atlas (1957) - se publicara un año después de La mentalidad anticapitalista (1956) de Mises. En la novela, Rand da ribetes novelescos a la teoría del autor sobre la selección gladiatoria de la especie que explicaremos a continuación.

La autora Ayn Rand adquiere fama en Estados Unidos a través de dos novelas El Manantial (1943) y la citada La Rebelión del Atlas (1957). En ambas se traslucen sin mucha dificultad las claves del código moral 'objetivista' con el que da vida al homo agens gladiador racional/capitalista- de Mises. El adjetivo "objetivista" de la ética que propugna se debe a que las normas o patrones que guían la acción humana afirma la autora - no son el resultado de un capricho subjetivo, sino que emanan de una realidad con existencia independiente de la conciencia del hombre. La premisa principal de esa constatación fáctica es que la cuestión de la vida y la muerte que enfrentan los organismos vivos requiere establecer un código de valores. El valor - lo deseable o adecuado- es la supervivencia. No hay alternativas. "La vida de un organismo es su patrón de valor; lo que ayuda a su vida es bueno, aquello que la amenaza es malo» (Rand, 1961, p. 24).

Sin embargo, no ha de confundirse a la vida con un derecho innato a sobrevivir. Esta representa solo un valor ganado y conservado a través de un proceso dinámico de acción. En otras palabras, afirma la autora, la vida es "aquello que se requiere para la supervivencia del hombre como tal» (Rand, 1961, p. 33). La clave para comprender esa equivalencia entre 'vida' y 'medios para' estriba en establecer la conexión vida-propiedad, ya que «sin el derecho a la propiedad, no es posible ningún otro derecho» (Rand, 1961, pp. 135-136). Por lo tanto, disponer del 'derecho' a vivir - afirma Rand - «no es una garantía de que un hombre obtendrá una propiedad, sino únicamente una garantía de que será suya si la gana». ¿Qué ocurre si no obtuviese el resultado esperado? Simplemente no se tiene la capacidad moralmente legítima de preservar su vida, ya que la ley de naturaleza «le prohíbe la irracionalidad» (Rand, 1961, p. 137). Pero, ¿qqué es ser racional? La racionalidad del hombre no es una condición, sino una elección. Significa, por ejemplo, elegir mantenerse "con una concentración mental absoluta en toda circunstancia, en todas las elecciones, en todas las horas de vigilia». Este estado de 'atención consciente' permite comprometerse a «que nunca se buscará o concederá lo no ganado o lo inmerecido, ni en materia ni en espíritu (la virtud de la Justicia)» (Rand, 1961, pp. 37-38) ${ }^{10}$.

Esta línea de argumentación lleva a la siguiente conclusión: fallar en el discernimiento de la realidad objetiva implica un uso erróneo de la condición humana racional. Pero, sobrevivir aprovechándose de los logros ajenos no reviste solo un fallo, sino una renuncia a lo humano, ya que solo la violencia física animal explicaría ese comportamiento.

Puede abandonar su método de supervivencia, su mente, puede transformarse en una criatura subhumana y puede convertir su vida en un breve lapso de agonía, así como su cuerpo puede existir durante un tiempo en proceso de desintegración por causa de una enfermedad. Pero como ente subhumano no puede triunfar, no puede alcanzar otra cosa que lo subhumano [...]. El hombre debe ser hombre por elección, y es obligación de la ética enseñarle de qué manera vivir como hombre (Rand, 1961, pp. 35-36).

La ética objetivista se encamina, por consiguiente, a enseñar a los hombres que la búsqueda del propio interés no implica una confrontación con otros, sino 
una relación sin sacrificios en la que dos individuos buscan racionalmente preservar su vida y alcanzar la felicidad. Recurriendo al concepto de Immanuel Kant sobre 'el reino de los fines', Rand afirma que «los intereses racionales de los hombres no chocan, que no hay conflicto de intereses entre hombres que no desean lo que no han ganado, que no hacen sacrificios ni los aceptan, y que tratan entre sí como comerciantes, entregando un valor por cada valor recibido» (Rand, 1961, p. 45). La sociedad agrede al hombre cuando le solicita una contribución adicional a su aporte en la división del trabajo y el comercio, por ejemplo, sosteniendo a aquellos que no pueden hacerlo por sí solos. Forzar un intercambio altruista supone obligar de forma inmoral a lo irracional.

De las páginas de las novelas randianas, al igual que en la obra reseñada de Mises, no se erigen solitarios sus míticos personajes Howard Roark o John Galt. Manadas populistas de 'zánganos perezosos' emergen blandiendo a las viciadas instituciones políticas para detenerlos. La política - 'kriptonita' mal habida de los perdedores-, cercena aquello que nació virtuoso, libre y exitoso. Mientras tanto, se reitera el llamamiento a emular al incorruptible Roark o al mítico Galt. No desearlo implica sumirse en la irracionalidad de lo subhumano. ¿Quién se opone al héroe sino el antihéroe? En resumidas cuentas, diría Ayn Rand, sus personajes no dañan a nadie. Ridícula invención la que acometen al responsabilizarlos del fracaso ajeno. Solo al emprendedor libertariano se le permite esgrimir excusas. Si tiene éxito lo debe a su entereza y libertad de pensamiento. Los estrepitosos fracasos se contabilizan en la responsabilidad de un 'otro' subhumano. Los íconos de la ética 'objetivista', al igual que el mercado libre, han de permanecer inmaculados. Ambos se exoneran en la medida en que siempre cabe alegar un intervencionismo remanente, excusa imperecedera de un proyecto siempre inconcluso demandante de mayores sacrificios.

\section{LA FANTASÍA NEUROLIBERAL}

La socialidad impuesta por el neoliberalismo consiste en constreñir los 'sujetos posibles' al binomio ganador/perdedor. Negar las consecuencias de las malas decisiones denota una separación neurótica con respecto a sí mismos (Mises, 2011, p. 27), que arroja al sujeto a la categoría de 'subhumano' (Rand, 1961, pp. 35-36). Resulta ocioso aclarar por nuestra parte la ausencia de toda vocación retórica al referirnos a dicha ideología como un 'mecanismo de selección social y de la especie'. Si sumáramos un pormenorizado detalle de los grandes desequilibrios sociales que sus políticas arrastran estaríamos adentrándonos en el frondoso bosque de las perogrulladas.
No obstante, tampoco podemos recurrir a 'la idiotez del insensato populacho' para explicar los ecos que encuentran los aparatos ideológicos del neoliberalismo. En este tercer apartado aplicamos el marco teórico propuesto por Žižek y Butler para explicitar la operatividad de la interpelación de Mises y Rand sobre individuos vulnerables a unas condiciones de posibilidad que escapan a su control. En este contexto el zarandeo de pruebas empíricas sobre la incongruencia entre la realidad de los exitosos-fracasados con su descripción por la ética gladiatoria carece de sentido. Por el contrario, buscamos describir los mecanismos por los cuales la figura del 'fracasado' delata la imposibilidad misma de la realidad social fantástica del neoliberalismo. El perdedor en la lucha a vida o muerte en el peligroso escenario de un mundo-mercado configuraría, según la crítica que aquí desplegamos, un modo alternativo de canalizar la obediencia hacia la aserción ilógica, injusta e irracional de que la desigualdad representa el germen de la prosperidad.

El dilema del sujeto consiste en saberse mediado por un poder exterior - nunca se es enteramente uno mismo-, pero preferir continuar en la existencia negándose a ver su formación en la subordinación. Sin embargo, los mecanismos de subjetivación se encuentran limitados por su propio fracaso en la sujeción. El desafío político consiste, por tanto, en encontrar los medios para reutilizar aquello que somos y subvertir la universionalidad de nuestro vínculo individual con el Estado (Butler, 1997, p. 114). En el siglo XX existen sonados ejemplos de inversiones o desbordes. En particular, el imaginario subversivo nuestroamericano demuestra que la esperanza, siempre superior al miedo disciplinario, funge la liberación de todo determinismo. 'Mujer', 'marica', 'cabecita negra', 'piquetero', 'desocupado', 'aborigen', 'negro', 'cholo', 'lepero', 'gaucho', interpelaciones habilitadas originalmente de forma injuriosa que lograron reterritorializarse y subvertirse. Dicho de otro modo, son apelativos que anuncian la capacidad de transformar el poder que constituye al sujeto en el poder al que este se resiste.

Sin embargo, no debiéramos caer en el romanticismo de las batallas finales e imaginarnos el momento y el lugar en el que se acontezca el gran rechazo. La captura de los aparatos del Estado ha demostrado su ineficacia para derrumbar los poderes que interpelan al sujeto desde su individualidad. Los episodios localizados tampoco alcanzan a inscribirse en la historia salvo cuando ocasionan efectos sobre toda la red de significaciones a la que se encuentran prendidos (Foucault 2002, p. 18-19). La eterna juventud del neoliberalismo nos recuerda, a su vez, la precariedad de los logros alcanzados. Lo cual nos lleva a preguntarnos cuáles son sus bases operacionales. Es decir, ¿cuál es la base de reproducción del neoliberalismo para poder contener los desbordes emancipatorios y 
continuar produciendo sujetos con necesidades sincronizadas con intereses sistémicos?

En respuesta presentamos la nomenclatura alternativa de 'neuroliberalismo' con la que explicitamos el basamento ideológico del neoliberalismo en la producción insidiosa de una subjetividad a la que se le oculta no solo el Otro, sino también, y fundamentalmente, el propio deseo ${ }^{11}$. En otras palabras, el sistema de ideas que describimos con el neologismo de propia cosecha 'neuroliberalismo' tiene por objeto impedir neuróticamente toda reacción a las demandas de una cultura suicida. La tesis que aquí arriesgamos es que su reproducción se sustenta en un doble movimiento. Por un lado, sirve como catalizador de una serie multiforme de dispositivos que sostienen la vigencia y legitimidad de un supuesto comportamiento económico-racional que ha de guiar las elecciones vitales individuales. Por otro lado, esa 'racionalidad' implica una decodificación de la realidad social en términos gladiatorios -i.e. normas de juego 'objetivas' para un escenario en el que no se garantiza la vida, sino la pugna por adquirir los medios para preservarla. A ese código le damos el nombre de 'ética gladiatoria'. El carácter subordinado del goce a la productividad del sistema mantiene a la experiencia vital dentro del paradigma de la lucha por la existencia, forzando, así, la renuncia en interés del orden, la seguridad y el éxito.

La homogeneización se posibilita a partir de la «fantasía ideológica» (Žižek, 2010a, pp. 201-256) ${ }^{12}$. Este mecanismo busca explicar que el fetichismo en las sociedades actuales no se ubica en el 'saber' sino en el 'hacer'. Los hombres 'saben' de la inexistencia del sujeto 'hecho a sí mismo' bajo cuya sombra adquiere significado la noción de libertad, igualdad, justicia, democracia, mercado, Estado, etc. Dicho de otro modo, nadie se toma en serio el mito randiano del 'atlas' que en virtud de su fuerza individual se opone al devenir mecánico de la historia culminando por sostener el mundo sobre su propia cabeza. A pesar de ello, se actúa 'como si' los campeones de la lucha en el mercado fuesen la materialización concreta de esa esencia titánica. En el campo social estas 'creencias' se materializan en prácticas concretas que reproducen las prácticas normadas. La ilusión es doble. La fetichista que orienta las prácticas sociales y la 'ilusión inconsciente' o fantasía que reprime - pasa por alto- que la autoridad de las mismas carece de verdad.

La obediencia 'externa' no reclama aceptación ni por sumisión a la fuerza bruta, ni por efecto de la falsa conciencia, ni por convicción interna. Tres instancias en las que la subordinación no procede del proceso de enunciación de la norma, sino que se encuentra mediada. Por el contrario, la condición positiva de la Ley consiste en que los individuos suscriban su mandato, aun sabiendo el carácter contingente, irracional e incomprensible. De ahí que este fetichismo de la 'práctica' denote un núcleo traumático que lejos de obstaculizar la sujeción, se constituye en su insumo básico (Žižek, 2004, p. 166), (Butler, 2002, p. 270). La fantasía es productiva de los mismos horrores que busca 'pasar por alto'. El sujeto es capturado por un goce que hace eco en sus reivindicaciones narcisistas que estructuran el conjunto de 'como si' encubridores de su propia explotación. Las prácticas normadas que debe realizar ritualmente se siguen de dicha deformación, brindando materialidad al aparato ideológico neuroliberal ${ }^{13}$.

Queda invertida entonces la noción marxista clásica de 'falsa conciencia'14. La fórmula tradicional de $E I$ capital -ellos no lo saben, pero lo hacen- se ve alterada y precisada por esta otra: «el sujeto cínico está al tanto de la distancia entre la máscara ideológica y la realidad social, pero pese a ello insiste en la máscara» (Žižek, 2010a, pp. 55-64). El progreso de lo animal -lo dado-a lo humano - lo deseado- requiere ignorar cínicamente las cadenas artificiales impuestas a la práctica libre, sustituyendo todo principio de placer por un realismo totalizador (Sloterdijk, 2003, pp. 37-45). Detengámonos en este doble juego al que se encuentra sometido el hombre. Por un lado, no cabe considerar al sujeto como el resultado del dominio, sino que debe aceptarse que en él se encuentra el lugar de asunción y reiteración del poder en su efectividad disciplinaria (Butler, 2010, pp. 21-29). Esta ambivalencia del proceso de sujeción - según esgrime el neuroliberalismo- brindaría legitimidad al sistema de expropiación constante de la satisfacción individual. En la medida en que se necesita producir esa plusvalía del goce para mantener en funcionamiento a la máquina productiva, su expropiación forma parte de los requerimientos sistémicos. La responsabilidad en la producción de sí como sujetos sometidos vendría a exculpar esa predación.

Sin embargo, hemos dicho que el cinismo reprime la práctica consciente de la servidumbre voluntaria. En Crítica de la razón cínica, Peter Sloterdijk hace referencia a la 'razón cínica' para diferenciar la ingenuidad de la falsa consciencia marxista de la paradoja de la 'falsa consciencia ilustrada'. Esta razón «se sabe desilusionada y, sin embargo, arrastrada por la 'fuerza de las cosas'» (Sloterdijk, 2003, p. 41). Para el cínico carece de sentido negar el interés particular de las construcciones universales de la ideología. Es decir, prescinde de 'ocultar la realidad' cuando se dispone de la capacidad de producir fantasías (inconscientes) que, a pesar de toda distancia irónica, estructuren las prácticas sociales. El cinismo estriba, precisamente, en aceptar y reconocer el interés particular que hay tras las instituciones del mercado, pero continuar usando al unísono la máscara de los derechos universales. 
En la vida cotidiana pocos, por no decir nadie, ignoran que cuando un gurú neuroliberal describe el valle de lágrimas hacia la prosperidad individual está obviando referirse a la ganancia que extraerán las corporaciones. No hay ocultamiento. En la era del neuroliberalismo la conciencia de las relaciones sociales no está oculta, sino mediada por una serie de soportes que posibilitan la ilusión inconsciente de que la sociedad construida a la medida del mercado resuelve todos los conflictos. La producción de subjetividad desplegada por el aparato ideológico de las corporaciones estriba, precisamente, en que los individuos conozcan y acepten la privatización de toda producción social, la enajenación de sus propias satisfacciones, porque precisamente ahí, en esa carrera por la acumulación, se juega la propia felicidad. En este contexto en el que la 'fuerza de las cosas' arrastra la reiteración de la sujeción, la emancipación, depende más de la adquisición de saberes prácticos para mejorar el desempeño, que en revisar las mismas relaciones de producción. Así, sin estar organizados por un director de orquesta, los sujetos actúan dentro de los límites inherentes a las condiciones particulares de producción de esos saberes. No los gobiernan los derroteros de un determinismo mecánico, sino las coerciones y las restricciones presupuestas al mercado en tanto que Coliseo perfecto para la lucha por la supervivencia. Este control a priori de una libertad encorsetada por prácticas posibles o concebibles impone un 'habitus'.

Puesto que el habitus es una capacidad infinita de engendrar, con total libertad (controlada), unos productos - pensamientos, percepciones, expresiones, acciones - que siempre tienen como límite las condiciones histórica y socialmente situadas de su producción, la libertad condicionada y condicional que él asegura está tan alejada de una creación de novedad imprevisible como de una simple reproducción mecánica de los condicionamientos iniciales (Bourdieu, 2001, pp. 86-89).

La internalización de esos condicionamientos iniciales que les brinda autoridad incondicional depende, según hemos dicho, de su experimentación como un mandato traumático, sin sentido. La economía inconsciente que elude la figura antagónica es la «fantasía ideológica» (Žižek, 2010a, p. 173). Esta no busca en la realidad un punto de fuga, sino estructurar la conciencia para que de forma ilusoria pase por alto el plus no integrado. En consecuencia, no hay un repliegue hacia una insondable profundidad oculta, sino una exterioridad material del inconsciente a través de las prácticas ideológicas, el cual queda expuesto en esa materialización (Žižek, 2010b, p. 11). Así, el sujeto capturado por la fantasía no soporta seguir soñando, es decir, presentarse frente a sus deseos no incorporados, ni incorporables ${ }^{15}$. Esa imposibilidad requiere que se suspenda el sueño y se busque refugio en una ilusión de resultado igualmente insoportable, pero significa- da a través de los vítores al exitoso. De esa manera, cuando la felicidad no acontezca, la ritualización de las prácticas continúa soportando la preadaptación de los agentes a un conjunto de acciones posibles, o posibilitadas. Como el caso en el que un individuo llega a su hogar y se divierte frente a la televisión. Unas risas pregrabadas le recordarán que él se está divirtiendo aun cuando esté sentado en su sillón medio adormilado luego de un día de trabajo idiota.

\section{CONSIDERACIONES FINALES}

La producción de subjetividad, hemos dicho, ni es mecánica, ni acontece de una vez y para siempre. En la repetibilidad necesaria se evidencian los intersticios donde corresponde ejercer la libertad y despertar las conciencias de la ilusión. Sin embargo, la ruptura del sueño ideológico no supone un abrir los ojos para que, con una mirada libre y cuerda, puedan observarse los hechos en su realidad. La distorsión ideológica no puede superarse ${ }^{16}$. La crítica supone, en cambio, confrontar las figuras discursivas dominantes con los deseos de los sujetos que en ellas se anuncian. Es decir, advertir, por ejemplo, en la figura del 'zángano que vive del éxito ajeno', no ya una falsedad objetiva, sino un intento por remendar las incongruencias de la ilusión neuroliberal. En otras palabras, advertir la atribución arbitraria sujeta a disputa hegemónica.

La ética objetivista del Coliseo descrito por Mises y Rand estructura los elementos heterogéneos de la sociedad en su existencia fantástica, fijando el punto vincular en el 'equilibrio' mecánico y espontáneo de intereses individuales en pugna permanente. Desplazan el antagonismo del cuerpo social, hacia un antagonismo de los 'productores' con el elemento disruptivo del éxito del capitalismo: las manadas subhumanas que irracionalmente pretenden distribuir el botín ajeno. Al reconocer este elemento del edificio ideológico que representa dentro de él ese antagonismo, se rompe el sueño y se habilita el camino hacia la renegociación tanto del sistema de exclusión interno al campo ideológico, como del campo en su totalidad.

En resumen, la sociedad de individuos que triunfan en un Coliseo no existe. La coordinación total donde la lucha por la vida no implique choque ni conflicto, tampoco. Su imposibilidad no se origina en las agresiones anticapitalistas que bloquean el éxito alcanzable por los gladiadores del mercado, sino en el fracaso estructural de cualquier intento por totalizar el campo social. En este trabajo hemos buscado invertir el vínculo de causalidad entre el revés de la sociedad neuroliberal y el 'zángano'. En consecuencia, este último no representa el obstáculo para alcanzar la normal operatividad, sino el punto en el que adquiere sonoridad el rechinar de una máquina que no alcanza a funcionar. La fantasía del neuroliberalismo como 'mecanismo 
de selección social y de la especie' supone, entonces, la forma que tiene el capital para adelantarse y disimular ese bloqueo inmanente (antagonismo). Puesta en escena que señala, por ejemplo, a los populismos 'intervencionistas' para llenar el espacio vacío de sus fallas constitutivas: guerras, crisis económicas, hambruna, pobreza, etc. Esta amabilización de la catástrofe anunciada es la función de la 'fantasía ideológica' que aquí describimos.

La fuerza fascinante del aparato ideológico del mercado estriba, precisamente, en su capacidad para proyectar la violencia inaugural que constriñe a los sujetos posibles al binomio éxito/fracaso, hacia los sectores más pauperizados de la sociedad. Así, lejos de advertir que el exitoso culmina ocupando una posición apenas distinta en la misma cadena de sometimiento y dominio que el fracasado, se habilitan narraciones 'humanitarias' que buscan enmendar los excesos a través de pequeños ajustes que 'desarrollen las capacidades' de los 'menos aventajados'. Entrampados en este círculo virtual de una pecera sin tabiques de poco serviría la eliminación de los obstáculos impuestos por el Consenso de Washington si los peces se mantuviesen voluntariamente adoctrinados a nadar en círculos intentando solo limpiar el agua de una pecera que ya no existe. En la proliferación de una ética alternativa a la 'rapacidad del mercado' estriba la clave para 'atravesar' la fantasía e, identificándonos en el otro, reconocer la verdad sobre nosotros mismos.

\section{NOTAS}

1 La noción de 'desventura' surge de un corrimiento hacia la historia para detectar una ruptura fatal que no debía producirse. "Accidente trágico, desgracia inaugural, cuyos efectos no dejan de ampliarse hasta el punto de que se desvanece la memoria de lo anterior, hasta el punto de que el amor por la servidumbre ha sustituido al deseo de libertad» (Clastres, 2005, pp, 33-48).

2 El calificativo posesivo 'nuestroamericano' hace referencia a la acepción originalmente acuñada por el pensador cubano José Martí en su célebre ensayo "Nuestra América» (1891), donde se sostiene el orgullo patrio suscitado por dolorosas repúblicas que deben incorporar a sus "masas mudas de indios» como elementos salvíficos, junto a los negros, a los campesinos y a los trabajadores, con ayuda de la «juventud angélica», para urdir una tierra libre, un hombre nuevo y real (Martí, 2005, pp. 14-15, p. 21 y p. 24)

3 En Anarquía, Estado y Utopía, Robert Nozick acepta la libertad para venderse uno mismo como esclavo (Nozick, 1990, p. 331). El individuo 'propietario de sí mismo' al buscar su bienestar siempre está en la posibilidad de renunciar a dicha propiedad y enajenarla. Sería un abuso que otros intervengan en dicha decisión para determinar aquello que no le está permitido emprender con su propiedad. Argumentos similares aportan autores como Thomson, 1990, p. 283-84; Steiner, 1994, p. 232; Block, 2003, pp. 39-85; Kershnar 2003, pp. 510-536.

4 Además de la obra de Marx, existen otros trabajos en los que se 'desmiente' el mito de la acumulación originaria (List, 1909); (Ha-Joon Chang, 2002), y también centrando el tema en Nuestramérica (Calcagno y Calcagno, 1995). Incluso los propios autores neoliberales ya no requieren ocultar que la acción básica del hombre en el mercado pasa por 'patear la escalera' por donde ellos han alcanzado el éxito económico. En un mundo capturado por el neoliberalismo los argumentos humanitarios se vuelven invisibles al no reflejar nada. Los significantes de los que depen- de dicha argumentación se convierten en ilusiones vacías. Al reprimirse la necesidad subjetiva de cambiar la realidad, pareciera que ya no hay nada que transformar.

5 Hayek, Friedrich, "Entrevista», El Mercurio, 19 de abril 1981 reproducida en Santa Cruz 2000, pp. 45-59. Cf. Vergara Estévez, 2014.

6 Eduardo Lonardi y Pedro Eugenio Aramburu gobernaron de facto Argentina desde el 16 de septiembre de 1955 al 1ㅇ de mayo de 1958. El golpe cívico-militar que encabezaron se autoproclamó ‘Revolución Libertadora'. El mejor compendio del pensamiento que inspira la dictadura cívico-militar de 19551958, se encuentra en El libro negro de la segunda tiranía (publicado en 1958 sin sello editorial). La primera adjudicada a Juan Manuel de Rosas, y la segunda, evidentemente, a Juan Domingo Perón. Redactado por la 'Comisión Nacional de Investigaciones' ordenada por Lonardi, resume las medidas dictadas para legitimar la proscripción impuesta sobre el peronismo que duraría 17 años más. Dicha comisión buscó «saber cómo y hasta dónde se había realizado su obra destructora». Las elecciones de 1946 y 1952, consideradas precarias mayorías adquiridas con astucias e intimidaciones, otorgan al 'tirano huido' el título de 'dictador elegido'. Para sus redactores, el grave error conceptual radica en considerar que la estabilidad democrática descansa en el apoyo electoral multitudinario. El consentimiento auténtico del pueblo, que fundamentaría quitarle el adjetivo de dictador, lo recibe el 'gobierno de la Revolución Libertadora'. La democracia, por tanto, no ha de pasar por el engorroso procedimiento electoral. En otras palabras, la democracia, por paradójico que resulte, adquiere alternativamente la calidad de electiva o de facto.

7 El general Juan Domingo Perón, líder del Partido Justicialista, participó activamente en el derrocamiento del presidente Ramón Castillo en 1943. Pero no ocupó el cargo de presidente sino 
hasta 1946, tras ser elegido por una amplia mayoría en elecciones democráticas el 14 de febrero de ese mismo año. Fue elegido presidente a través de elecciones libres en dos ocasiones más (1952 y 1973).

8 Citamos en inglés este párrafo debido a que en la edición casteIlana dirigida por Federico Frischknecht - Secretario de Prensa y Turismo de la dictadura de J. C. Onganía, 1967-1969- están eliminadas las referencias de Mises sobre Perón.

9 El nombre de 'Escuela Austríaca' es acuñado por Gustav von Schmoller para referirse despreciativamente a la obra de Carl Menger, quien publicó el trabajo fundacional de dicha escuela Principios de Economía Política, en 1883. Hacia finales del siglo XIX se produjo una primera ola de trabajos a la que se suman Eugen von Böhm-Bawerk y Friedrich von Wiese que criticaban tanto a Karl Marx, como a la escuela historicista alemana de Schomoller. En el siglo XX, Ludwig von Mises y su estudiante Friedrich Hayek realizaron extensos aportes (Mises, 1986), (Hayek, 1964).

10 La negación del derecho a la vida de forma autónoma a la posesión material de medios la difunde Ayn Rand, pero son muchos los autores del neoliberalismo norteamericano y austríaco que la aceptan -Nozick, Friedman o Hayek. Por ejemplo, Nozick critica la definición del egoísmo de Rand (Nozick, 1997, pp. 249264), sin embargo, acepta la premisa sobre la imposibilidad de fundamentar el derecho a la vida sin sustentarlo en una teoría de la propiedad privada (Nozick, 1990, p. 179).

11 Esta acepción la hemos introducido en diferentes trabajos anteriores: Identidad argentina y compromiso latinoamericano (Lanús: UNLa, 2009); en la conferencia ¿Neoliberalismo o neuroliberalismo? que clausuró el $V$ Workshop internacional sobre Darwinismo Social y Eugenesia organizado por la Unidad de Ciencias Humanas del IIB-INTECH/CONICET-UNSAM en noviembre de 2012; "¿Neoliberalismo o neuroliberalismo? Emergencia de la ética gladiatoria», Utopía y Praxis Latinoamericana, Venezuela, 4. vol. 18, no 62, (jul-sep, 2013) pp. 13-34; y en ¿Neoliberalismo o Neuroliberalismo? Editorial Universidad Nacional, Costa Rica, en prensa. El elemento compositivo 'neuro' con el que describimos al neoliberalismo no hace referencia a la neuropolítica, ya que prescindimos de una explicación fisiológica de lo que describiremos en este trabajo como 'sujeción voluntaria'. Aunque no profundicemos directamente en el empleo de las neurociencias en el campo de lo social, sí vale destacar que la referencia tangencial es insoslayable, ya que estas ponen especial énfasis en la imbricación entre adoctrinamiento y reproductividad del sistema neoliberal. El mercado engulle a lo político recurriendo a los mismos métodos para capturar al 'cliente' votante. La mera posibilidad de comprender cómo activar en los sujetos deseos sincronizados con los intereses de los grupos de poder ha funcionado como un 'grial'.

12 Butler, aunque difiere en las derivas políticas que el autor le brinda a su teoría, elogia la potencialidad abrasiva de la crítica ideológica que emprende Žižek (Butler, 2004, p. 31-35).

13 La materialidad de la opresión ideológica es señalada desde distintas perspectivas (Althusser, 2011, p. 131-144), (Marcuse, 1969, p. 58), (Bourdieu, 2001, pp. 76-89).

14 Según la teoría marxista, la identificación del individuo con la fuerza que lo oprime se origina en la 'falsa conciencia'. Sujetos ingenuos que no conocen la realidad de sus relaciones sociales, reiteran con sus actos la sujeción a lo que los oprime. La verdad, o los poderes ocultos, de la ley que los oprime queda tras un velo de ignorancia.

15 Žižek emplea la interpretación lacaniana de los sueños para explicar el funcionamiento de la determinación ideológica. Según Lacan, en el sueño nos acercamos al núcleo duro de nuestros deseos, ya que despiertos no somos más que 'la consciencia de este sueño' (Lacan, 1999).

16 Aunque con diferencias Butler y Žižek se esfuerzan por alejarse de una posición que identifique a dichos residuos con un núcleo recóndito que las prácticas de subjetivación no llegan a representar. Para ambos el sujeto no es nada más que el fracaso del intento de simbolización (Žižek, 2004, p. 166), (Butler, 2002, p. 270 y 2010 , pp. 21-41) 


\section{BIBLIOGRAFÍA}

Alarcón, Cristian (2002), Cuando me muera quiero que me toquen cumbia. Vida de pibes chorros. Buenos Aires, Norma.

Althusser, Lois (2011), La filosofía como arma de la revolución. Buenos Aires, Siglo XX.

Block, Walter (2003), "Toward a Libertarian Theory of Inalienability," Journal of Libertarian Studies, 17 (2): pp. 39-85.

Bourdieu, Pierre (2001), El sentido práctico. Madrid, Taurus.

Butler, Judith (2002), Cuerpos que importan. Sobres los límites materiales y discursivos del 'sexo'. Buenos Aires, Paidós.

Butler, Judith (2004), “Reescenificación de lo universal: hegemonía y límites del formalismo". En: Butler, Judith, Ernesto Laclau y Slavoj Žižek (eds.), Contingencia, Hegemonía y Universalidad. Diálogos contemporáneos en la izquierda, Buenos Aires, Fondo de Cultura económica.

Butler, Judith (2010), Mecanismos psíquicos del poder: teorías sobre la sujeción. Valencia, Cátedra.

Calcagno, A. E.; Calcagno, A. F. (1995), El Universo neoliberal. Recuento de sus lugares comunes. Buenos Aires, Alianza.

Clastres, Pierre (2005), "Libertad, Desventura, Innombrable". En: Ferrer, Christian (comp.), El lenguaje libertario. Antología del Pensamiento Anarquista Contemporáneo, La Plata, Terramar.

Cortázar, Julio (1963), Rayuela. Buenos Aires, Sudamericana.

Crouch, Colin (2012), La extraña no-muerte del neoliberalismo. Buenos Aires, Capital Intelectual.

Cucinotta, Antonio et. al. (2002), Post-Chicago developments in antitrust law. Chettenham, Edward Elgar.

Duschatzky, Silvia y Cristina Corea (2004), Chicos en banda. Los caminos de la subjetividad en el declive de las instituciones. Buenos Aires, Paidós.

Fisher, Karin y Plehwe, Dieter (2013), "Redes de think tanks de intelectuales de derecha en América Latina", en Nueva Sociedad, 245 , pp. $70-83$.

Foucault, Michel (2002), Vigilar y castigar: nacimiento de la prisión, Buenos Aires, Siglo XXI Editores.

Friedman, Milton (1980), Free to choose: a personal statement, Harmondsworth, Penguin.

Friedman, Milton (1977), Friedman on Galbraith and on Curing the British Desease, Londres, The Fraser Institute.

Galbraith, John Kenneth (1992), La cultura de la satisfacción, Buenos Aires: Emecé.

Hayek, Friedrich (1964), "The Theory of Complex Phenomena". En: Bunge, Mario (ed.), The Critical Approach to Science and Philosophy. Essays in Honor of K. R. Popper, MacMillan Publishing Co.
Hayek, Friedrich (1978), Temas de la hora actual, Buenos Aires, Bolsa de Comercio de Buenos Aires.

Hayek, Friedrich (1981), “Entrevista”, Revista Realidad, Santiago, 24.

Hayek, Friedrich (1989), Camino de servidumbre, Madrid: Libro Libre.

Ha-Joon Chang (2002), Kicking Away the Ladder, Development Strategy in Historical Perspective, Londres, Anthem Press.

Kershnar, Stephen (2003), "A Liberal Argument for Slavery," Journal of Social Philosophy, 34 (4), pp. 510-36.

Kessler, Gabriel (2004), Sociología del delito amateur, Buenos Aires, Paidós.

Lacan, Jacques. (1999), Los cuatro conceptos fundamentales del psicoanálisis: 1964, El seminario de Jacques Lacan Libro 11, Buenos Aires, Paidós.

Lakoff, George (2011), No pienses en un elefante: lenguaje y debate político. Madrid, Editorial Complutense.

List, Friederich (1909), The National System of Political Economy by Friedrich List, trans. Sampson S. Lloyd, with an Introduction by J. Shield Nicholson, London: Longmans, Green and Co.

Marcuse, Herbert (1969), Psicoanálisis y política, Barcelona, Península.

Martí, José (2005), Nuestra América, Buenos Aires, Ed. Nuestra América.

Marx, Karl (1999), El Capital, trad. W. Roces, tomo I, México, Fondo de Cultura Económica.

Megay, Edward N. (1970), "Anti-Pluralist Liberalism: The German Neoliberals", Political Science Quarterly, 85 (3), p. 440.

Mises, Lugwig von (1953), La acción humana, tratado de economía, Madrid, Unión Editorial, 1986.

Mises, Margit von (1984), My Years with Ludwig von Mises, lowa, Center for Futures Education.

Mises, Ludwig von (2006), Economic Policy. Thoughts for Today and Tomorrow, Alabama, Ludwing von Mises Foundation.

Mises, Ludwig von (2011), La mentalidad anticapitalista, Madrid, Unión Editorial.

Nozick, Robert (1997), Socratic Puzzles, Londres, Harvard University Press.

Nozick, Robert (1990), Anarquía, Estado y Utopía, Buenos Aires, Fondo de Cultura Económica.

Rand, Ayn (1961), La virtud del egoísmo. Un nuevo y desafiante concepto del egoísmo, Buenos Aires, Grito Sagrado.

Rand, Ayn (1975), El manantial, Barcelona, Planeta, 1975.

Rand, Ayn (2008), La rebelión de atlas, Buenos Aires, Grito Sagrado, 2008. 
Santa Cruz, Lucía (2000), Conversaciones con la libertad, Santiago, El Mercurio y Aguilar.

Sloterdijk, Peter (2003), Crítica de la razón cínica, Madrid, Ediciones Siruela.

Steiner, Hillel (1994), An Essay on Rights, Oxford, Blackwell.

Thomson, Judith Jarvis (1990), The Realm of Rights, Cambridge, MA, Harvard University Press.

Vergara Estévez, Jorge (2014), "Hayek y la modernización chilena”. En: Biagini, Hugo y Fernández Peychaux, Diego, ¿Neoliberalimo o neuroliberalismo?, pp. 219-244, Costa Rica, Universidad Nacional, en prensa.

Wacquant, Loïc (2004), Las cárceles de la miseria, Buenos Aires, Manantial.
Willgerodt, Hans y Peacock, Alan (1989), "German Liberalism and Economic Revival", en Germany's Social Market Economy: Origins and Evolution, Londres, MacMillan,

Žižek, Slavoj (2004), “¿Lucha de clases o postmodernismo? ¡Sí, por favor!”. En: Butler, Judith; Laclau, Ernesto y Žižek, Slavoj (eds.), Contingencia, Hegemonía y Universalidad. Diálogos contemporáneos en la izquierda, Buenos Aires, Fondo de Cultura económica.

Žižek, Slavoj (2010a), El sublime objeto de la ideología, Madrid: Siglo Veintiuno.

Žižek, Slavoj (2010b), El acoso de las fantasías, Madrid: Siglo Veintiuno. 